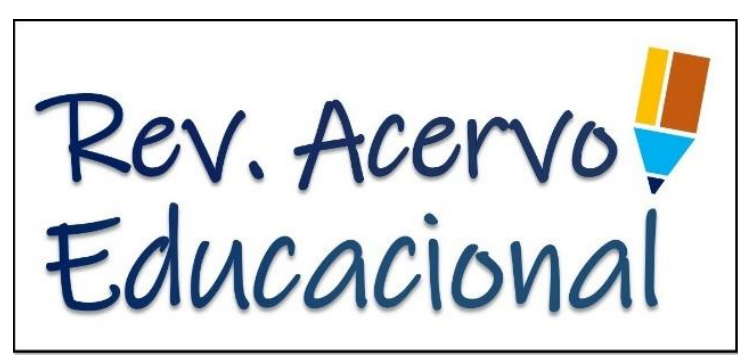

REVISÃO BIBLIOGRÁFICA

Recebido em: 7/2019

Aceito em: 7/2019

Publicado em: 8/2019

\title{
O Ensino de Física e as Energias Renováveis
}

\author{
Physics Teaching and Renewable Energies \\ Enseñanza de Física y Energías Renovables \\ Edson Araujo da Silva ${ }^{1 *}$.
}

\begin{abstract}
Resumo: A Física Clássica, que é ensinada no Ensino Médio está baseada nas teorias de Isaac Newton, mas ela não consegue explicar todos os fenômenos da natureza, surge então, no início do século XX, a Mecânica Quântica, sendo utilizada para demonstrar, entre tantas coisas, como um material semicondutor (silício) poderia ser empregado em painéis fotovoltaicos para transformar a luz do sol em energia elétrica. E necessário que ocorram mudanças curriculares e na forma de ensinar e aprender, neste sentido a Aprendizagem Significativa coloca os conhecimentos prévios, que o estudante traz de sua vida em sociedade, no centro do processo de aquisição de novos saberes. A geração de energia renovável, para mais de um bilhão de pessoas, é um desafio no qual a Ciência tem um papel central, levando essa discussão além de uma questão técnica, uma vez que sem energia elétrica, alguns países, continuarão condenados à fome e ao subdesenvolvimento.
\end{abstract}

Palavras-chave: Ensino de Física; Aprendizagem Significativa; Energias Renováveis.

\begin{abstract}
Classical Physics, which is taught in high school is based on the theories of Isaac Newton, but it cannot explain all the phenomena of nature, so, at the beginning of the twentieth century, Quantum Mechanics was used to demonstrate, among others. So many things as a semiconductor (silicon) material could be employed in photovoltaic panels to turn sunlight into electrical energy. It is necessary that changes occur in the curriculum and in the way of teaching and learning, meaningful learning places the previous knowledge, which the student brings from his life in society, at the center of the process of acquiring new knowledge. Renewable energy generation for over one billion people is a challenge in which science plays a central role, taking this discussion beyond a technical issue, since without electricity, some countries, will remain condemned to starvation and underdevelopment.
\end{abstract}

Keyword: Physics Teaching; Meaningful Learning; Renewable Energies.

Resumen: La física clásica, que se enseña en la escuela secundaria se basa en las teorías de Isaac Newton, pero no puede explicar todos los fenómenos de la naturaleza, por lo que surge, a principios del siglo veinte, la mecánica cuántica, utilizada para demostrar, entre otros. Se podrían emplear tantas cosas como material semiconductor (silicio) en paneles fotovoltaicos para convertir la luz solar en energía eléctrica. Es necesario que se produzcan cambios en el plan de estudios y en la forma de enseñar y aprender; el aprendizaje significativo colocá-los los conocimientos previos que el estudiante aporta de su vida en la sociedad, en el centro del proceso de adquisición de nuevos conocimientos. La generación de energía renovable para más de mil millones de personas es un desafío en el que la ciencia juega un papel central, llevando esta discusión más allá de un problema técnico, ya que sin electricidad, algunas países, seguirán condenados a la inanición y el subdesarrollo.

Palabras clave: Enseñanza de la Física; Aprendizaje Significativo; Energías Renovables.

1 Universidade Federal Rural do Rio de Janeiro, Instituto Federal de Educação, Ciência e Tecnologia do Amazonas; Instituto Federal Campus Manacapuru-AM. *E-mail: edsonn10@yahoo.com.br 


\section{INTRODUÇÃO}

O ensino da Física parece estar preso a concepções do século XIX, entretanto poderia e deveria estar centrado nas novas descobertas científicas que surgem na atualidade e são amplamente divulgadas, tanto em artigos científicos quanto nos meios de comunicação de massa. Pensando em novos rumos para o ensino poderíamos modificar o currículo da disciplina e com isso seríamos capazes de trabalhar com conceitos que explicariam, por exemplo, como nas próximas décadas o desenvolvimento de computadores quânticos e, consequentemente, uma "inteligência artificial" possibilitarão que avanços científicos e tecnológicos aconteçam de forma exponencial, e como resultado seremos capazes de elucidar alguns desafios que hoje, teoricamente, são insolúveis.

Porém, no Brasil, a Física no Ensino Médio ainda é lecionada por docentes sem a formação apropriada ou, pior ainda, sem a titulação na disciplina, agravado pela falta de políticas públicas que incentivem a requalificação desses profissionais, para que possam contribuir significativamente com a aprendizagem e formação de uma educação científica, ainda mais, os discentes que ingressam no Ensino Médio não possuem a proficiência mínima em ciências exatas, número de aulas limitadas em oposição à grande quantidade de conteúdos a serem lecionados, alguns deles desatualizados, estimulando uma aprendizagem mecânica, restringindo os estudantes a resoluções de exercícios sem reflexões e questionamentos. Como ensina FREIRE P (1988), o ensino está centralizado no conhecimento do professor em detrimento do discente, numa concepção bancária de educação e segundo Moreira MA (2017), compete a essa educação apassivar ainda mais os estudantes, adaptando-os ao convívio em sociedade, tornando-se assim 'bem-educados'.

De acordo com os Parâmetros Curriculares Nacionais (2002), a Física tem que contribuir para formação de um cidadão contemporâneo, atuante e solidário, com instrumentos para compreender, intervir e participar da realidade. Esse objetivo ambicioso esbarra em condições de trabalho adversas para a maioria dos docentes, que se dividem em várias escolas tentando garantir um mínimo de rendimento para sua subsistência. Conforme Kawamura MR e Hosoume Y (2003), receitas prontas de ensinar não se aplicam à educação e é fácil designar parâmetros e diretrizes sem estar em sala de aula e vivenciar todos os seus desafios e contradições.

Precisamos mudar a forma de ensinar e aprender e Moreira MA (2017) sugere uma concepção dialógica, pois o educando tem que se apropriar dos conteúdos de forma a relacioná-los com sua história, cultura e fatores sociais envolvidos nos processos. A Teoria da Aprendizagem Significativa de AUSUBEL D (2000) é ideal nesse processo e o estudante deve assumir um papel fundamental na sua formação; ainda segundo o autor, existe uma utilização inadequada da teoria da Aprendizagem Significativa, mas na prática, "no chão da sala de aula" os conteúdos ainda são trabalhados de forma mecânica e memorística.

Conforme explica Moreira MA (2017), para a Aprendizagem Significativa, o fator de maior relevância são os saberes que o aprendiz já possui e como ele interliga as novas ideias a esses conhecimentos prévios, de forma a resignificar conceitos relevantes na sua estrutura cognitiva, para atingir esse objetivo o estudo da energia é ideal por permear várias disciplinas.

A utilização de energia na produção de um determinado trabalho foi uma conquista da Ciência, na Grécia antiga já se estudava esse conceito, embora hoje haja algumas definições para essa grandeza, a energia não pode ser completamente explicada devido estar imbricada em todos os fenômenos estudados na Física. Como ensina Goldemberg J e Lucon O (2007), o ser humano retira a energia necessária para viver da água, oxigênio e alimentos, esta máquina fascinante, possui a mesma potência de uma lâmpada 100 watts.

Para Goldemberg J e Chu S (2010), nos países desenvolvidos há um consumo exagerado de energia, em níveis que estão causando um perigoso desequilíbrio. Como iremos gerar e distribuir essa energia de forma sustentável é a resposta que a Ciência irá buscar no século XXI, uma vez que o desenvolvimento da raça humana sempre esteve ligado à sua capacidade de produzir e usar essa energia.

Um esforço mundial é liderado pela Organização das Nações Unidas (ONU) buscando impor limites a essa política neoliberal que tem um de seus pilares na globalização, ao incentivar a confecção, em larga escala, 
de produtos demandantes cada vez mais de energia e insumos para sua produção, essa verdadeira "montanha" de produtos precisa ser consumida e a propaganda se encarrega de convencer consumidores alienados de que sua vida só terá sentido com a aquisição destes produtos, na sua grande maioria supérfluos. De acordo com Freire $\mathrm{P}$ (1992), temos que fazer oposição à receita neoliberal que aborta o sonho dos homens em nome das facilidades do consumismo irracional do capitalismo.

Como escapar desta armadilha e reparar os danos e impactos socioambientais que já foram causados ao planeta constitui-se num grande desafio para a humanidade, assim sendo, enquanto não conseguimos todas as respostas, carecemos, mais do que nunca, trabalhar cada um na sua ambiência, porém em unidade, para preservarmos nosso planeta.

Esse artigo tem como objetivo propor um novo olhar sobre o ensino de Física e com isso discutir mudanças que incluam novos conteúdos que sejam relevantes para os estudantes e os envolva no processo de aprendizagem significativa.

\section{REVISÃO BIBLIOGRÁFICA}

A Mecânica Quântica surgiu há pouco mais de um século e seu desenvolvimento interfere no cotidiano de todas as pessoas, para Kawamura MR e Hosoume Y (2003), os livros didáticos da disciplina tratam de forma superficial inovações nas telecomunicações, internet, telefonia celular ou na área de diagnóstico médico, esses avanços seriam impossíveis de acontecer sem a contribuição da Física.

Sobre a finalidade do ensino, Piaget $J$ (1982) defende que o principal objetivo da educação é formar homens capazes de fazer coisas novas, não apenas repetir o que outras gerações já criaram. A segunda meta da educação é formar cidadãos preparados para criticar, verificar e não aceitar tudo o que a eles se apresenta, nesse sentido portanto, é necessário que o educador esteja aberto para uma nova realidade, compreendendo que ainda há muito a aprender, e isto exige que ele se dispa da presunção de ser o detentor da verdade, desenvolva sua audição, respeitando os saberes e arranjos locais.

A nova Base Nacional Comum Curricular (2017) explica que essas competências devem ser trabalhadas com os discentes para que eles possam; analisar situações-problema e avaliar aplicações do conhecimento científico e tecnológico e suas implicações no mundo, utilizando procedimentos e linguagens próprios das Ciências da Natureza, para propor soluções que considerem demandas locais, regionais e/ou globais, e comunicar suas descobertas e conclusões a públicos variados.

A Física, enquanto disciplina que estuda os fenômenos naturais, pode contribuir para que os estudantes enxerguem com clareza acontecimentos, como efeito estufa ou o ciclo da água, que estão interligados ao tema energia, de maneira que agregue um significado para o conteúdo, o que, além de gerar uma Aprendizagem Significativa, criará também o devido respeito ao consumo consciente de energia.

Existe um consenso internacional de que a forma como a energia no mundo está sendo gerada causa um desequilíbrio que não é sustentável a longo prazo. "A Conferência Mundial para o Meio Ambiente e Desenvolvimento, realizada no Rio de Janeiro em 1992 e, especialmente, a publicação do World Development Report, (Relatório sobre o Desenvolvimento Mundial,1992), do Banco Mundial, consolidaram a primeira versão do conceito de "desenvolvimento sustentável" segundo Lemos CF (2004).

Levantamentos, feitos de acordo com Goldemberg J e Lucon O (2007), apontam para uma medida de sustentabilidade chamada "ecological footprint" ou "pegada ecológica", que mede a área produtiva necessária para assimilar os rejeitos que são produzidos por uma determinada população com um certo padrão de vida. Em 1999, a "pegada" de cada habitante do planeta era de 2,3 hectares (ou $23 \mathrm{mil} \mathrm{m}^{2}$ ). Em 2050, seu valor total será o dobro da capacidade da Terra.

Como avaliam Goldemberg J e Chu S (2010) temos hoje, aproximadamente, 2,4 bilhões de pessoas usando carvão vegetal, lenha, resíduos de agricultura ou esterco como seu principal combustível para cozinhar, enquanto 1,6 bilhão de pessoas no mundo todo vive sem eletricidade. 
O desenvolvimento da ciência e da tecnologia, de forma indireta, ajudou a criar o problema e cabe a todos contribuir para a sua solução, para Lemos CF (2004), através de práticas sociais, com foco na sustentabilidade e em arranjos locais, baseados na aquisição de benefícios para não expropriar, mas valorizar os saberes dessas comunidades.

O físico-químico Svante Arrhenius descobriu em 1896, estudando a queima de combustíveis fósseis como o petróleo, que a combustão acresceria a quantidade de dióxido de carbono na atmosfera, aumentando a temperatura de todo o planeta; criando então a expressão até hoje utilizada em todo o mundo: efeito estufa. Contudo ainda não se tinha consciência das implicações para o meio ambiente, de acordo com Oliveira HT (2007), atualmente acreditamos que a educação ambiental deve promover a reflexão na ação, entendida como práxis educativa, e que nos permita identificar problemas e conflitos relativos às nossas ações e à nossa própria presença no planeta, condicionada por nossa forma de pensar, nossos valores, nosso tempo histórico, nossa cultura etc. e que reflete igualmente nossas escolhas cotidianas como produtores e consumidores de bens e serviços. Para alcançar este objetivo, além da organização do poder público, que deve orientar, legislar e fiscalizar ações que possam causar danos e impactos socioambientais, é preciso que haja um movimento de conscientização e sensibilização de toda a sociedade e a escola tem um papel fundamental neste processo.

De acordo com a Teoria da Aprendizagem de Ausubel DP (2000), o conceito fundamental é a aprendizagem significativa, na qual os conhecimentos prévios, trazidos pelos discentes da sua ambiência, irão fundir-se às novas ideias a eles apresentadas, formando uma nova rede de percepções, que segundo Moreira MA (2017) é um maneira pela qual uma nova informação conecta-se, de maneira essencial e não aleatória, a um aspecto importante da estrutura cognitiva do estudante, para que esse processo aconteça é fundamental que ele já possua alguns conhecimentos sobre o tema apresentado que evoluem para proposições mais elaboradas, através de um processo constante de ressignificação; ainda para o autor, essa transformação seria a diferenciação progressiva, ou seja, uma sequência de atribuição de novos significados a um dado conceito resultante da contínua utilização dessa ideia para dar sentido a novos conhecimentos.

A aprendizagem significativa acontece quando uma nova informação se alicerçar em ideias indispensáveis, já existentes na estrutura cognitiva do estudante. De acordo com Ausubel DP (2000), as estruturas cognitivas são construídas por ordem de importância dos conceitos, que são representações de experiências perceptíveis para o indivíduo, organizando-se de forma hierárquica em termos de nível de subjetividade, generalidade e exclusividade de seus conteúdos. Em outras palavras, os novos conhecimentos que se adquirem relacionam-se com o conhecimento prévio que o discente possui, o autor ainda define este conhecimento anterior como conceito que já existia nas estruturas de conhecimentos específicos que podem ser mais ou menos extensos, de acordo com a regularidade com que ocorre aprendizagem significativa, resultando no crescimento e na mudança do conceito.

Essa nova forma de produzir conhecimentos e avaliar, segundo Silva EC (2015) citando Ausubel DP (2000), recomenda que a avaliação da Aprendizagem Significativa não pode ser apenas resultado final; deve ser também uma construção onde as atividades podem ser refeitas, permitindo que o estudante repare as atividades de aprendizagem. Este modelo se opõe às certezas absolutas presentes nas avaliações de múltipla escolha, ao apresentar apenas uma resposta, porque mesmo com as dificuldades de lidar com as dúvidas e as abstrações, surgem circunstâncias próprias para construir diálogos e relações entre os estudantes e professores. É como se os estudantes estivessem incluídos nos processos de avaliação, rompendo com os padrões vigentes na maioria das escolas, onde somente o professor tem o poder de avaliar o trabalho dos discentes.

\section{CONSIDERAÇÕES FINAIS}

O ensino de Física necessita de uma reestruturação curricular e as novas tecnologias presentes em nosso cotidiano devem estar sempre ligadas aos conteúdos lecionados em sala de aula. Novas formas de ensinar e aprender, como a Teoria da Aprendizagem Significativa, estão indicando um caminho onde as experiências que esses aprendizes já trazem do seu cotidiano devem ser levadas em consideração e valorizadas na sala 
de aula. O tema Energias Renováveis está presente em várias disciplinas, e em particular na Física. Sendo iminente e desafiadora a geração de energia para mais de um bilhão de pessoas no mundo, faz-se imprescindível que estudantes e toda sociedade reflitam e contribuam para que países possam superar o subdesenvolvimento agravado pela falta de energia. É preciso incentivar a formação de mentes inquietas, que não permaneçam insensíveis aos anseios de sua comunidade, mas libertas para produzir novas formas de aprender e aproveitar, assim, o conhecimento de todos, sem preconceito, de forma proativa.

\section{REFERÊNCIAS}

1. AUSUBEL DP. Aquisição e retenção de conhecimentos: Uma perspectiva cognitiva. Lisboa. Paralelo Editora LDA, $2000 ; 227 \mathrm{p}$.

2. BRASIL. Base Nacional Comum Curricular (BNCC). Ministério da Educação, Secretaria de Educação Continuada, Alfabetização, Diversidade e Inclusão; Secretaria de Educação Profissional e Tecnológica. Conselho Nacional de Educação; Câmara de Educação Básica, 2017; 576 p.

3. BRASIL, Ministério da Educação, Secretaria de Educação Média e Tecnológica. Orientações Educacionais Complementares aos Parâmetros Curriculares Nacionais (PCN): Ciências da Natureza, Matemática e suas Tecnologias. Brasília: Ministério da educação, 2002.

4. FREIRE P. Pedagogia da Esperança: um reencontro com a Pedagogia do Oprimido. São Paulo: Paz e Terra, 1992; $127 \mathrm{p}$.

5. GOLDEMBERG J, CHU S (coordenador). Um futuro com energia sustentável: lluminando o caminho. Amsterdam: Inter Academy Council; Rio de Janeiro: Academia Brasileira de Ciências, 2010; 299 p.

6. GOLDEMBERG J, LUCON O. Energias Renováveis: Um futuro sustentável. Revista USP, São Paulo, n.72, 20062007; p. 6-15.

7. KAWAMURA MRD, HOSOUME Y. Explorando o ensino de Física, v. 07, SAEB, 2003; p. 22-27.

8. LEMOS CF. Energia na Amazônia: caminho para o desenvolvimento ou aprofundamento da exclusão? In: II Encontro da Associação Nacional de Pós-Graduação e Pesquisa em Ambiente e Sociedade - ANPPAS, 2004, Indaiatuba, São Paulo, 2004; 20 p.

9. MOREIRA MA. Grandes desafios para o ensino da Física na educação contemporânea, vol. 1; Brasília, Revista do professor de Física, 2017; p.18-31.

10. OLIVEIRA HT. Educação Ambiental - ser ou não ser uma disciplina: essa é a principal questão?. In: Mello, S.S.\& Trajber, R.. (Org.). Vamos cuidar do Brasil: conceitos e práticas em educação ambiental. 1a.ed. Brasília - DF: MEC/CGEA, MMA/DEA, UNESCO, 2007; 244 p.103-112.

11. PIAGET J. A Formação do Símbolo na Criança: imitação, jogo e sonho, imagem e representação. 3. ed. Rio de Janeiro: Zahar, 1978; $356 \mathrm{p}$. 